\title{
La anticoagulación prolongada previene las recurrencias luego de un tromboembolismo venoso
}

A comparison of three months of anticoagulation with extended anticoagulation for a first episode of idiopathic venous thromboembolism. Kearon C, Gent M, Hirsh J. N Engl J Med. 1999; 340:901-907.

\section{Objetivo}

Evaluar si la prolongación del tiempo de tratamiento reduce la observación de recurrencias de tromboembolismo venoso sintomático y, secundariamente, evaluar si el hallazgo de alteraciones trombofílicas frecuentes (Factor $V$ Leiden- anticuerpos antifosfolípidos o la mutación del gen de protrombina) identifica subgrupos de mayor riesgo de recurrencia.

\section{Diseño}

Ensayo prospectivo, aleatorizado, doble ciego, con una media de seguimiento de diez meses.

Luego de haber sido tratados durante tres meses, se aleatorizó a los pacientes a dos grupos: extensión del tratamiento dicumarínico (RIN 2-3) o tratamiento con placebo.

\section{Lugar}

Estudio multicéntrico realizado en 12 centros de Canadá y Estados Unidos.

\section{Pacientes}

Pacientes consecutivos con diagnóstico de trombosis venosa profunda (TVP) sintomática y/o tromboembolismo pulmonar (TEP) confirmados objetivamente, sin factores predisponentes mayores, que hubieran cumplido tres meses de tratamiento convencional (83 pacientes en la rama de placebo y 79 en la de warfarina). Se incluyeron pacientes con tromboembolismo venoso previo si tal evento se había producido en relación con factores de riesgo transitorios.

\section{Medición de resultados}

Eventos tromboembólicos recurrentes confirmados objetivamente.

\section{Resultados}

El estudio se suspendió prematuramente debido a la menor recurrencia de eventos tromboembólicos en el grupo tratado. La tasa de tromboembolismo venoso recurrente luego de diez meses de seguimiento medio (análisis intermedio preespecificado*) fue de 1.3 cada 100 pacientes/año (IC95\%: 0.0 a 4.7) en el grupo con warfarina y de 27.4 cada 100 paciente/año (IC95\%: 14.4 a 40.4) en el grupo placebo ( $p$ 0.001). La diferencia absoluta entre los grupos fue de 26.4 eventos cada 100 pacientes/año (IC95\%: 12.9 a 39.4), resultando la warfarina en un $95 \%$ de reducción de riesgo (IC95\%: 63 a $99 \%)$.

La tasa de complicaciones hemorrágicas mayores (no se observaron fatales) fue de 3.8 cada 100 pacientes/año (IC95\%: 0.0 a 8.1) en el grupo warfarina. De los tres episodios hemorrágicos, dos ocurrieron en pacientes con RIN mayor al indicado.

Excepto para los pacientes con anticoagulante lúpico, los parámetros bioquímicos evaluados no discriminaron subgrupos de riesgo de recurrencia.

\section{Conclusiones}

Los pacientes con un primer episodio de trombosis venosa idiopática deberían ser tratados con anticoagulación por más de tres meses sin que la duración optima de dicho tratamiento haya sido determinada.

\section{COMENTARIO}

Los resultados de este estudio pueden tener un importante efecto en el tratamiento de pacientes con TVP. Aunque los resultados parecen sorprendentes, la terminación precoz del estudio podría llevar a sobreestimar la magnitud real del beneficio de la anticoagulación, como señalan los propios autores. El efecto podría ser algo menor de haber sido completado según lo diseñado, sobre todo habiéndose calculado en 95 el número de pacientes necesarios en cada rama para detectar una diferencia, con un error a* de 5\%. Este 5\% implica en este trabajo que esa es la probabilidad de concluir incorrectamente que la extensión del tratamiento dicumarínico reduce la tasa de tromboembolismo venoso recurrente. Aún así, dada la importancia de la diferencia hallada, la posible sobrestimación no modificaría la conclusión. La inclusión de pacientes con troembolismo previo probablemente tampoco modifique las conclusiones. Cabe aclarar que información proveniente de otros trabajos contempla la conducta en aquellos pacientes con un segundo episodio de trombosis . En base a estos datos y a otros de la literatura, para decidir la duración del tratamiento dicumarínico, se puede clasificar en tres grupos a aquellos pacientes que presentan con un primer episodio tromboembólico: ${ }^{1}$. Pacientes con factores predisponentes al momento del evento y que no persisten más allá del mismo: tres meses de anticoagulación. 2. Pacientes con factores de riesgo persistentes: continuación del trata- miento miemtras persistan los factores.

3. Pacientes con tromboembolismo venoso idiopático: de acuerdo a los datos de este estudio, continuación del tratamiento dicumarínico más allá de tres meses.

Según este promisorio estudio, el NNT* para prevenir una recurrencia es de 4 pacientes/año.

Queda abierto el interrogante acerca de la duración óptima de la terapéutica. Según los datos de este trabajo, el $76 \%$ de las recurrencias se produjeron dentro de los seis meses de iniciado el estudio y el $88 \%$, dentro de los doce meses (si bien no parece alcanzarse una meseta durante el tiempo total de evaluación).

La tasa de complicaciones hemorrágicas mayores es concordante con otros datos publicados, pero es importante no extrapolar resultados sin considerar el contexto en el cual se desarrolla el seguimiento.

El intento de hallar anormalidades bioquímicas en relación con predisposición trombótica señala que ninguno de ellos puede utilizarse para la decisión de la continuación o no del tratamiento. Debe señalarse que la población de pacientes al momento de su inclusión en este estudio no fue considerada sobre la base de los criterios actuales de "trombofília" lo que requiriría su consideración en forma separada.

*Ver Glosario

Dra. Alicia Murúa Medicina Interna.Médica Hematóloga. 